ASEE's 123rd Annual • Conference \& Exposition • New Orleans, LA • June 26-29, 2016

\title{
Leading Team Learning: Reflections of a Teaching Assistant
}

Mr. Brian E Faulkner, University of Illinois, Urbana-Champaign

Brian Faulkner is a graduate student at the University of Illinois at Urbana Champaign. His interests include teaching of modeling, engineering mathematics, textbook design, and engineering epistemology. 


\title{
Leading team learning: Reflections of a Teaching Assistant
}

\begin{abstract}
Active learning models have been propagating through engineering education. As this process occurs, many graduate students must lead new forms of active learning instruction which they themselves have never experienced as a learner. Team learning workshop environments have become more common, and this paper shares some "tricks of the trade" from the perspective of a first-time teaching assistant. Included are instructional temptations to avoid, tips to improve student group function, and ways to improve your teaching technique.
\end{abstract}

\section{Introduction}

Active learning pedagogy is steadily gaining acceptance and use in engineering classrooms. As these techniques gain more acceptance, more of the front-lines teaching assistants (TA's) will be called upon to implement these methods. However, many TA's have not experienced active learning techniques during their own education as undergraduates. While there are resources on the implementation of these programs, ${ }^{3}$ advice for the novice practitioner of active learning can be more difficult to find. The purpose of this paper is to share my experience with one active learning model, in hopes that other instructors can learn from it and pick up a useful technique or prevent a mistake. In the spirit of the 'tricks of the trade' theme of this session, this article is written informally, speaking directly to you, the reader. The purpose of this article is to provide advice and experiences from an experienced TA to help novice graduate teaching assistants. The informal style is chosen to make the article easy, and perhaps a little fun, to read and absorb. This article is a rigorous reflection, not a formal research study, so there won't be the usual methods, results, or discussion sections. Instead, expect tips such as "Don't isolate female students" or "Always solve worksheets yourself before class." The tips in this article are supported by documented experiences in my classroom and when appropriate also by references to the education literature.

Context determines how much of the advice here is transferable to your particular program. An overview of the program at my university is provided to allow the reader to decide which of these tips are relevant for their particular institutional context. This paper relates my experiences with the team learning workshop model in the MERIT program, during fall semester 2015 in the introductory electronics course (ECE 110) at a large, research-based university in the American Midwest. The MERIT program uses small group team learning workshops, which is 
similar to but distinct from a typical discussion or recitation section. These workshop classes improve freshman student retention, particularly among underrepresented demographics. ${ }^{8}$ MERIT classes typically have 16-32 students working together in groups of three or four, lead by a graduate TA. The special MERIT section meets once a week, and is worth 1 credit hour on students' transcripts in addition to the credit hours from the primary course (much like lab sections). MERIT is not a remedial section. The students work problems that are very difficult for the median freshman. Each problem takes a group of four students an hour or two to solve. Problems are more open-ended than homework or exam problems and demand substantial thinking from the students. Students are evaluated on attendance and participation, rather than the completeness or correctness of their solutions. In this environment students have ample time to really understand concepts, rather than race toward the correct solution. After completing a worksheet, the group must explain and justify their work to the TA, and if it is found satisfactory they move on to the next worksheet. The MERIT program is targeted at underrepresented students in ECE, hoping to create social relationships among students within their discipline and encourage students to persist in the major.

\section{TIP: The palest ink is better than the sharpest memory. Keep a journal of workshop sessions.}

"One student said in an email that the TA (myself) gave too many hints and didn't let them construct their own knowledge. My internal reaction was 'This cannot be! I'm so vigilant about hints!' However, upon reviewing my record of the previous class session, I had recorded giving that group several hints, and even commented that I had perhaps given too many!"

While leading the workshop session, jot down short notes in a notebook about what hints you gave, what questions students asked, and how students interacted with one another. Reconstitute them into a typed report as soon as class is over if possible; the memory fades quickly. A good journal report will make the reader feel like they were there when reading the journal entry. The journal is an excellent way to keep the lecturers of the main course informed of how things in the special section are going. Rather than taking time out of their day to observe occasionally, you can take an hour to do a detailed write up. One faculty member commented that he could earnestly defend the value of the MERIT program in front of the department, because he really felt like he knew what was going on in the sessions thanks to my write-ups. Furthermore, keeping a journal will allow you to recognize your weaknesses as a teacher and improve your teaching abilities. It is from this journal that all the other tips in this article are derived.

The principles for writing a good journal are much like the principles for taking ethnographic field notes. ${ }^{6}$ Avoid vague quantifying phrases such as "I helped them for a while" and "They needed $a$ lot of hints to get started." These will be meaningless when you review the 
record a few days later or show it to an instructor. Instead use "I helped them for four or five minutes," or "They needed three hints to get started." A good journal records both the actions of the students and those of the TA. Strive to be specific about what happened, rather than your reaction to it or suspected motivations for that action. Keeping your journal detailed in this way will allow you to separate action from reaction, making it a more useful tool for later reflection.

\section{TIP: Put louder students on opposite sides of the table}

"James and Jian are two loud, dominant students (a white male and an Asian male, the majority in ECE), in a group with two quieter students, Mary and Hector (a white female and a Latino male, both underrepresented in ECE). At the beginning of the workshop session, James and Jian sat adjacent to one another and dominated discussion. They leaned toward one another to view each other's worksheets and talked loudly. Meanwhile, their teammates were quiet and disengaged. Noticing this, I asked the students to swap chairs, putting the two more dominant students on opposite corners of the table. Mary became drastically more talkative and offered far more ideas in the new arrangement."

Groups of four work very well, and are a typical suggested group size for team learning. ${ }^{3}$ I would like to share one practice that distinguishes groups of four from groups of three qualitatively. Often when a group of four sits down around a table, the two most loud, dominant students will sit adjacent to one another. These two students can then talk exclusively with one another, since they can read each other's work easily and are sitting close to each other. This can exclude and diminish the experience of the quieter students. Arrangement of seating is known to influence classroom activities. ${ }^{7}$ Rearranging the seating so that the two louder students are on opposite sides of the square is a simple and very effective solution to this problem. The more dominant students will see each other's work as upside down, and will start engaging the quieter students adjacent to them more. With groups of only three students, this simple and powerful option is taken away from you. The two more dominant students will always be able to read each other's work easily.

\section{TIP: Don't isolate female students.}

"Anne is in a group of four with John, Sarah and Kevin. However, today Sarah is absent. While working on the problem, John and Kevin talk mostly to each other, and Anne doesn't feel like she is being heard, even when her teammates are pursuing an incorrect solution. Her frustration builds until she excuses herself from class."

The acceptable integers for the number of females in a group are 0,2 and 3 . The research $^{1}$ indicates this is the best practice. My experiences leading a team-learning workshop 
have aligned with this policy. However, in a two-male, two-female group, a female student absent from class due to sickness or oversleeping can isolate her female teammate. Groups in this model are usually a little fluid, don't be afraid to rearrange groups just before class begins. Most students, male and female, will be absent at least once. To maintain flexibility, have a mixture of two-female and three-female groups. In the event of a female student's absence, you can swap in a female from a three-female group to create two groups with two females each. This can reduce the risk of an incident that requires direct intervention, and maintain a more productive learning environment for all students. The TA should construct groups, rather than letting them self-organize, to ensure positive group experiences for students. ${ }^{3}$

\section{TIP: Quiet students may be actively participating, watch for body language.}

"Kevin was quiet most of the class period. Rarely was his voice heard above his teammates. However, when I called upon him to explain the group's work, he was completely on-point and made insightful comments about the limitations of their solution. If not for this interaction, I might have deducted participation credit from him."

You don't have the same ability to read deeply into a single student's thinking when leading team learning workshops as you do during one-on-one tutoring. It is easy to mistake a quiet group for one that is not working or understanding. This may tempt you to give them more hints. Watch and listen carefully for a minute or two. They may be doing more than is immediately apparent. ${ }^{3}$ Furthermore, watch students from across the room. They may try to act productive only when you are nearby or directly engaging with their group. If a group is truly quiet and not participating, ask one student to explain to another and extract yourself from the conversation. $^{5}$

\section{TIP: Resist the temptation to spend more time with the more skilled students}

"Jake's group is very productive. He is leading the team and has asked an insightful question about the difference between parameters and variables. I spend a while answering this nuanced and advanced question, the group listening and asking follow-up questions. Meanwhile, the adjacent group is getting stuck on a basic issue of how sign conventions work and I have failed to notice."

The occasional student will remind you of yourself when you were an undergraduate. They think in a more advanced, abstract way and show genuine interest in the material. It is easy to spend extra time with these students, and in the team learning workshop this is an easy trap to fall into. However, you must be vigilant with yourself to allocate your time fairly. Students with more basic questions need your time just as badly, if not more so. Just like when a student asks 
question beyond the scope of the course in lecture, the appropriate response is often "That's a great question! But we don't have time to talk about that right now, please come speak to me after class." To identify when you are spending more time with one group, you can keep a running tally in your jottings notebook for each time you speak to each group. Review this tally at the midpoint of class and reallocate your time in the second half of the class session if necessary.

\section{TIP: Resist the temptation to give answers.}

The team learning workshop format works because students construct their own knowledge. ${ }^{3}$ If you have done one-on-one tutoring before, you have learned how to ask leading questions. While lecturing, you job is often to give the answers and show how to do things. The team learning workshop format is just dissimilar enough to both of these formats for your instincts to get crossed. You may feel like the class session will get out of control if you don't just give an answer and move to the next group with a hand up. Resist this impulse. These workshops require students to struggle with and triumph over difficult material. ${ }^{3}$ As said eloquently by Katzenbach, "This is the essence of the team leader's job: striking the right balance between guidance and giving up control." One way to avoid this it to answer a student question with another question. Asking the student about a definition or convention will often set them on the right track without directly providing an answer. Addressing the second group with a hand up directly can reduce the pressure you feel on yourself to move on. Saying "I'm helping this group right now, I'll get to you as soon as I'm done," will reassure yourself and the students.

\section{TIP: Set an expectation that cell phones are encouraged in class, but only for academic resources}

"On one problem, the students had to compute power draw for various household devices and design a household circuit breaker configuration. Some devices current draws were given (among them a hair dryer), the others were left blank (among them a flat screen TV) and instructed the students to look that information up online to complete the problem. The stark contrast between the high current draw of a hair dryer and the low current draw of a large flatscreen TV that they looked up really shocked the students. They disbelieved the number they found online for the TV, and this lead to a discussion of how light-producing and heat-producing devices have very different power demands."

Cell phones can be a distraction in class, but they can also be useful learning tools. You can engage students in their work by leaving information out of the worksheet that students must look up online. You can put QR codes into the worksheets, linking to device specification documents, encyclopedia entries, or tutorial pages. This can credibly demonstrate to students that 
you permit and encourage appropriate cellphone use in class. Of course, you must firmly discourage any non-academic use of devices during workshop class time when you observe it. After a few weeks, you will start seeing students using their phones to engage more deeply with the problems.

\section{TIP: Rotate which student explains the group's work.}

"Oh, your group is done with the worksheet? Great. Jeremy, would you like to explain? Ok, I'll come back when everyone is on the same page and can explain the group's work."

As teams of students solve the worksheets, sometimes a student gets left behind. However, faster students can gain much from explaining to slower students. ${ }^{5}$ To encourage this behavior, make sure to rotate who is explaining the group's work to you. The most dominant member of the group will almost always be the first to try to speak. Just calmly say "I would like Jeremy to explain for the group." If that student stumbles, just retreat and tell them you will come back when everyone understands. This way, the group knows that each student in their team must be accountable to explain the group's work.

\section{TIP: As a male TA, conscientiously phrase feedback to female students.}

"I am approaching Riley's group (which has three female students). Over the noise of the rest of the class, I hear her comment 'Now he's just going to tear us apart.' I had become an academic boogeyman who invited soul-crushing defeatism by dismantling their hard work."

When reviewing a student's' work, you must critique their reasoning and ask them to justify their solution (both when it is correct and when it is incorrect.) Ideally, you can do this through asking probing questions that lead them to conclude that their reasoning is flawed. However, the way that you criticise reasoning can be internalized, ${ }^{2}$ and lead to student anxiety toward showing you their work. Self doubt affects female students differently than it affects male students. ${ }^{3}$ This trepidation came only from my mostly-female groups of students. Be careful not to let critique of their work be interpreted as critique of the student. This attitude certainly caught me by surprise; I had never felt that way when a professor showed me the errors in my reasoning. However, this is a possibility you should be aware of. Watch out for it.

\section{TIP: Always solve the problems ahead of time, and have your solutions reviewed by a peer.}

"On one problem involving the Wheatstone Bridge, the worksheet told the students to find one of the voltages. I let the students wallow in forty minutes of frustrating linear algebra, when a quick 
intuitive assertion that the voltage was zero was all the head professor had intended with the worksheet."

Resist the temptation to lead problems without solving them first. You need to know where the sticky points of the problems are. ${ }^{3}$ Unlike exams, you cannot lead problems you have written but haven't fully solved. Always fully and completely solve the worksheets on your own, even if you have effortless expertise in this subject, even if you led the exact problem last year. When running a team learning session, you have to keep your eyes and attention in many places. Thinking about whether you really know these problems adequately saps precious attention. When another member of the instruction team creates a problem that you must lead, the intent of the problem may not be clear to you. Since these problems are more open-ended, this ambiguity can be an issue. Solving ahead of time allows you to confer with the creator of the worksheet to make sure you are interpreting the task correctly. Not doing so can mean dragging the students through far more work than the creator intended. Furthermore, not knowing how to solve a peer's problem that catches you by surprise damages your credibility to the students. If you didn't show up to class prepared, is it really fair to expect the students to do the same?

\section{Conclusion}

None of these situations will be universal to all implementations of team learning workshops, but many will transfer to most implementations. As active learning continues to grow, a community of expertise must grow around it, where TA's and instructors share experiences with these new pedagogies to improve their instruction as quickly and as easily as possible. I hope these tips and tricks will arm you with information for leading your own team learning workshops.

\section{Bibliography}

[1] Tonso, Karen L. "On the Outskirts of Engineering: Gender." Power, and Engineering Practice. Rotterdam (2007).

[2] Cohen, G. L., Steele, C. M., \& Ross, L. D. (1999). The Mentor's Dilemma: Providing Critical Feedback Across the Racial Divide. Personality and Social Psychology Bulletin, 25(10), 1302-1318. doi:10.1177/0146167299258011

[3] Roth, Vicki, Ellen Goldstein, and Gretchen Mancus. "Peer-Led Team Learning: A Handbook for Team Leaders." (2001).

[4] Katzenbach, J.R. and D.K. Smith (1993) The Wisdom of Teams. New York: Harper Business 
[5] Ilkhanipour Rooney, S., Schafer McGurk, J., Elliott, E. R., Williams, U. J., \& Dourte Segan, L. (2015). Facilitating the Transition of a Traditional Engineering Course to a Structured, Active, In-Class Learning Environment as a Teaching Assistant. 122nd ASEE Annual Conference \& Exposition, Paper ID \#11750.

[6] Bogdan, R. C \& Biklen, S. K. (2003). Qualitative Research for Education: An introduction to Theories and Methods (4th ed.). New York: Pearson Education group. (pp. 110-120).

[7] Barrett, P., Zhang, Y., Moffat, J., \& Kobbacy, K. (2013). A holistic, multi-level analysis identifying the impact of classroom design on pupils' learning. Building and Environment, 59, 678-689.

doi:10.1016/j.buildenv.2012.09.016

[8] Drane, D., Smith, H. D., Light, G., Pinto, L., \& Swarat, S. (2005). The gateway science workshop program:

Enhancing student performance and retention in the sciences through peer-facilitated discussion. Journal of Science Education and Technology, 14(3), 337-352. doi:10.1007/s10956-005-7199-8 